\title{
Article \\ Antimicrobial, Insecticidal and Cytotoxic Activity of Linear Venom Peptides from the Pseudoscorpion Chelifer cancroides
}

\author{
Jonas Krämer ${ }^{1}$, Tim Lüddecke ${ }^{2,3}$, Michael Marner ${ }^{2}{ }^{\circledR}$, Elena Maiworm ${ }^{2,4}$, Johanna Eichberg ${ }^{2,4}$, \\ Kornelia Hardes ${ }^{2,3,4}$, Till F. Schäberle ${ }^{2,5,6}{ }^{\circ}$, Andreas Vilcinskas $\left.{ }^{2,3,5}{ }^{(}\right)$and Reinhard Predel ${ }^{1, *}$
}

Citation: Krämer, J.; Lüddecke, T.; Marner, M.; Maiworm, E.; Eichberg, J.; Hardes, K.; Schäberle, T.F.; Vilcinskas, A.; Predel, R. Antimicrobial, Insecticidal and Cytotoxic Activity of Linear Venom Peptides from the Pseudoscorpion Chelifer cancroides. Toxins 2022, 14, 58. https://doi.org/ $10.3390 /$ toxins 14010058

Received: 30 November 2021

Accepted: 4 January 2022

Published: 14 January 2022

Publisher's Note: MDPI stays neutral with regard to jurisdictional claims in published maps and institutional affiliations.

Copyright: (C) 2022 by the authors. Licensee MDPI, Basel, Switzerland. This article is an open access article distributed under the terms and conditions of the Creative Commons Attribution (CC BY) license (https:// creativecommons.org/licenses/by/ $4.0 /)$.
1 Institute of Zoology, University of Cologne, Zuelpicher Strasse 47b, 50674 Cologne, Germany; j.krae12@gmail.com

2 Department of Bioresources, Fraunhofer Institute for Molecular Biology and Applied Ecology, Ohlebergsweg 12, 35392 Giessen, Germany; Tim.Lueddecke@ime.fraunhofer.de (T.L.); michael.marner@ime.fraunhofer.de (M.M.); elena.maiworm@ime.fraunhofer.de (E.M.); johanna.eichberg@ime.fraunhofer.de (J.E.); kornelia.hardes@ime.fraunhofer.de (K.H.); till.schaeberle@ime.fraunhofer.de (T.F.S.); andreas.vilcinskas@ime.fraunhofer.de (A.V.)

3 LOEWE Centre for Translational Biodiversity Genomics (LOEWE-TBG), Senckenberganlage 25, 60325 Frankfurt, Germany

4 BMBF Junior Research Group in Infection Research “ASCRIBE”, Ohlebergsweg 12, 35392 Giessen, Germany

5 Institute for Insect Biotechnology, Justus-Liebig-University of Giessen, Heinrich-Buff-Ring 26-32, 35392 Giessen, Germany

6 German Center for Infection Research (DZIF), Partner Site Giessen-Marburg-Langen, Ohlebergsweg 12, 35392 Giessen, Germany

* Correspondence: reinhard.predel@uni-koeln.de

\begin{abstract}
Linear cationic venom peptides are antimicrobial peptides (AMPs) that exert their effects by damaging cell membranes. These peptides can be highly specific, and for some, a significant therapeutic value was proposed, in particular for treatment of bacterial infections. A prolific source of novel AMPs are arthropod venoms, especially those of hitherto neglected groups such as pseudoscorpions. In this study, we describe for the first time pharmacological effects of AMPs discovered in pseudoscorpion venom. We examined the antimicrobial, cytotoxic, and insecticidal activity of full-length Checacin1, a major component of the Chelifer cancroides venom, and three truncated forms of this peptide. The antimicrobial tests revealed a potent inhibitory activity of Checacin 1 against several bacteria and fungi, including methicillin resistant Staphylococcus aureus (MRSA) and even Gram-negative pathogens. All peptides reduced survival rates of aphids, with Checacin1 and the C-terminally truncated Checacin $1^{1-21}$ exhibiting effects comparable to Spinosad, a commercially used pesticide. Cytotoxic effects on mammalian cells were observed mainly for the full-length Checacin1. All tested peptides might be potential candidates for developing lead structures for aphid pest treatment. However, as these peptides were not yet tested on other insects, aphid specificity has not been proven. The $\mathrm{N}$ - and C-terminal fragments of Checacin 1 are less potent against aphids but exhibit no cytotoxicity on mammalian cells at the tested concentration of $100 \mu \mathrm{M}$.
\end{abstract}

Keywords: pseudoscorpion venom; antimicrobial peptides; antimicrobial activity; cytotoxic activity; insecticidal activity; checacin; megicin

Key Contribution: The recently discovered Checacin1; which represents an abundant antimicrobial peptide from the venom of the pseudoscorpion C. cancroides; shows potent antimicrobial and insecticidal activity.

\section{Introduction}

One of the more prevalent medical challenges of our time is the emerging resistance of pathogenic bacteria to antibiotics. In the EU more than 33,000 deaths per year are attributed to infections with multi-resistant bacteria [1]. A possible strategy to address 
this issue is the discovery of novel compounds with antimicrobial activity. In this regard, antimicrobial peptides (AMPs) are a promising substance class. In contrast to established antibiotics, which normally act on specific cellular processes, AMPs usually exert their effect by disrupting the cell membrane of their target [2]. The specificity of these peptides depends, inter alia, on net charge and hydrophobicity [2] and many exhibit not only antimicrobial but also cytotoxic activities, which can hamper successful drug development [3].

A rich source for the discovery of novel AMPs are animal venoms. This has already been demonstrated by the discovery of many AMPs in the venom of, e.g., spiders, scorpions, snakes, insects, and cone snails [4-10]. Many of the AMPs discovered in venoms were found to be effective against a wide range of bacteria, including Methicillin-resistant Staphylococci e.g. [11,12]. For some AMPs, an apparent potential for the application against multi-resistant bacteria was already described. These AMPs include marcin and its orthologs from scorpion venom, which were effectively used to treat mice infected with multiresistant bacteria [13]. Interestingly, the main reasons for rejecting commercial development of scorpion AMP-based antibiotics were rather cost-related or the lack of improvement in efficiency compared to conventional antibiotics, but not the frequent problem of cytotoxicity against human cells [7]. Another application of these compounds is their use as specific pesticides. For instance, oral administration of AMPs from scorpion venom was shown to effectively reduce the number of pea aphids within three days by killing the aphid's symbiotic bacteria [14]. Hence, AMPs might be promising candidates for alternative pesticides against aphids, which belong to the most important agricultural pests [15]. To increase the chances of identifying novel and highly efficient AMPs, sampling across a wider taxonomic range is advisable.

One group of venomous animals that has been poorly studied regarding its venom composition but has recently been proposed as a potential priority group for bioprospection is the order of pseudoscorpions. Pseudoscorpions, for which more than 3600 species [16] were described, belong to the arachnids and thus share a common ancestor with other venomous lineages, such as spiders and scorpions [17]. Although the more prominent venomous arachnids usually overshadow the pseudoscorpions in the general perception, they nevertheless represent an important group for bioprospection [18]. Within these tiny arthropods, which mostly do not exceed a body length of a few millimeters, a unique venom delivery system has evolved: members of the suborder Iocheirata possess pedipalps equipped with a venom delivery system for subduing their prey. Knowledge about the venom composition of these animals is still limited to a very few species. In the past, the small size and associated handling problems, as well as the miniscule venom yield, have made a proteomic analysis of the venom particularly difficult. Initial studies comprised solely transcriptomic analyses, which provided first insights on the potential venom composition of two pseudoscorpion species $[19,20]$. However, the possibility of false positives cannot be ruled out when de novo transcriptomic approaches are solely used for the inference of venom compositions [21]. Very recently, a method for extracting pseudoscorpion venom has been developed and thus the implementation of proteomic approaches for studies on pseudoscorpion venom became possible. This enabled for the first time a comprehensive proteo-transcriptomic analysis of the venom composition of the house pseudoscorpion Chelifer cancroides [22,23]. These works also led to the discovery of checacins, the first potential AMPs identified from the venom of pseudoscorpions [22]. Checacins were classified as potential AMPs based on their similarity to megicin, an antimicrobial peptide found in the venom of the scorpion Mesobuthus gibbosus [24]. As high therapeutic potential has been described for megicin and orthologous sequences [13], checacins might also have beneficial properties in this regard. In our study, we examined the activity of Checacin 1 and some Checacin 1 fragments in different assays. First, we tested their antimicrobial activity on different strains of Gram-negative and Gram-positive bacteria as well as on different fungi. We also determined the cytotoxicity of the tested peptides to mammalian cells. Finally, their potential for use as pesticides was investigated using aphid feeding assays. 


\section{Results}

An overview of the peptides tested in the bioassays is given in Figure 1. In the venom of $C$. cancroides, Checacin1 is highly abundant, whereas the $\mathrm{N}$ - and $\mathrm{C}$-terminal fragments Checacin $1^{1-11}$ and Checacin $1^{12-25}$ occur naturally, but with lower abundance [18].

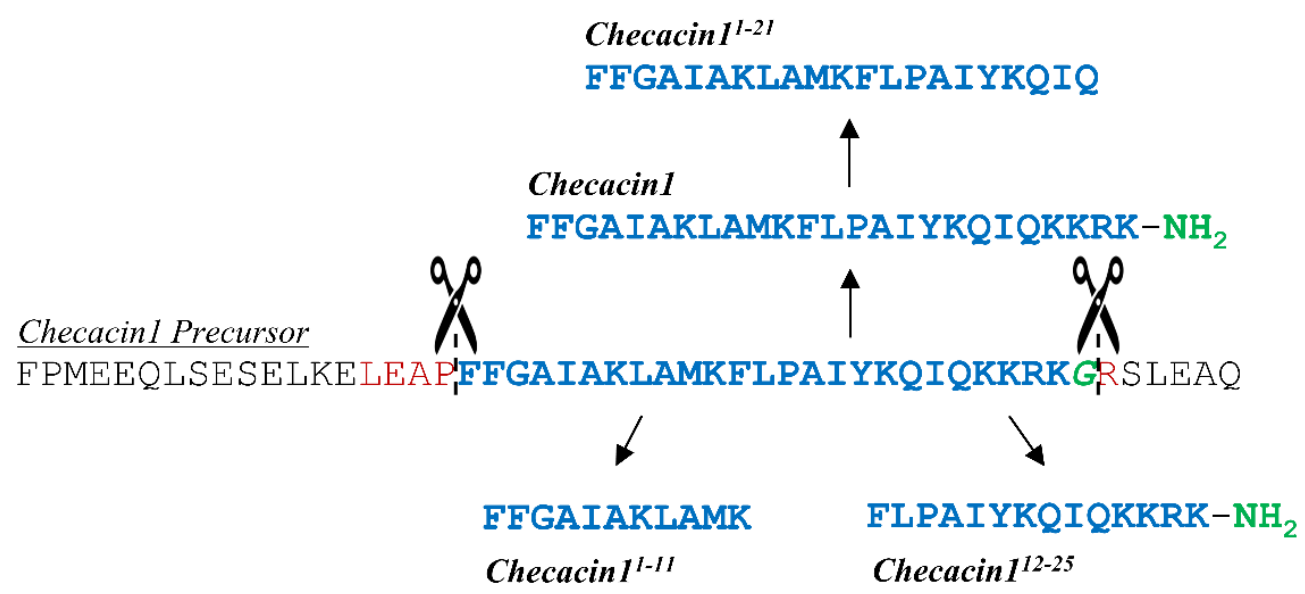

Figure 1. Precursor sequence of Checacin1 (without signal peptide) and the sequences used for the bioassays. Native Checacin1 is N-terminally cleaved at a highly effective 'LEAP' motif [22], which is typical of most checacin precursors [23]. The C-terminal cleavage of the Checacin1 progenitor is upstream of a monobasic (Arg) cleavage site and has a C-terminal amidation site (Gly). The preceding KKRK motif does not function as a cleavage signal [22]. Checacin $1^{1-11}$ and Checacin $1^{12-25}$ are naturally occurring fragments of Checacin1, while Checacin $1^{1-21}$ has not been detected in the venom of C. cancroides [22]. However, for the orthologous Megicin 18 from the scorpion M. gibbosus, the C-terminal cleavage was postulated to be upstream of such a tetrabasic motif [24].

\subsection{Checacin1 Is Highly Active against Bacteria and Fungi}

The minimum inhibitory concentration (MIC) of Checacin1 and the truncated Checacin1 fragments was determined for a diverse panel of Gram-negative and -positive bacteria as well as two fungal indicator strains (Table 1). In order to explore the translational potential of checacins regarding the development of antibiotics, clinically relevant microorganisms were included in the screening. Among these are methicillin-resistant Staphylococcus aureus (MRSA) and most importantly Pseudomonas aeruginosa as well as Escherichia coli. Mycobacterium smegmatis was screened as surrogate test organism for Mycobacterium tuberculosis. Yeasticidal efficacy was determined using Candida albicans as a surrogate strain for Candida auris. Only full-length Checacin 1 and the C-terminally truncated Checacin $1^{1-21}$ (only on S. aureus) exhibited an inhibitory effect on the tested organisms. Checacin1 inhibited the growth of all tested microbes, with the lowest MIC values found for E. coli and MRSA. No difference of Checacin1 potency towards E. coli could be observed when tested in bicarbonate supplemented medium (CAMH-C). With a MIC of $6.25 \mu \mathrm{M}, \mathrm{C}$. albicans is notably affected by application of Checacin1, while the growth of the filamentous ascomycete Aspergillus flavus was not inhibited.

\subsection{Orally Administered Checacin1 Is Active against Pea Aphids (Acyrthosiphon pisum)}

To evaluate aphid survival after oral application of Checacin1, aphids were monitored for three days. The aphid survival is compared to application of $\mathrm{MeOH}$ (negative control) and the pesticide Spinosad (positive control) in a survival curve (Figure 2, Table S1). Checacin 1 and, to lesser degree also Checacin $1^{1-21}$, caused a rapid decrease of the aphid survival rate similar to that of Spinosad (Figure 2a,b). Both killed about half of the aphids ( $54 \%$ and $58 \%$ respectively). For the Checacin 1 fragments (Checacin $1^{1-11}$, Checacin $1{ }^{12-25}$; Figure $2 \mathrm{~d}, \mathrm{e})$, the effect on aphid survival is much less distinct compared to the negative control, but still significant. 


\subsection{Cytotoxic Activity of Checacin1}

For assessing the cytotoxicity of Checacin1, a CellTiter-Glo ${ }^{\circledR}$ cell viability assay was conducted (Figure 3, Table S2). Cytotoxic effects on the MDCK II cells were mainly observed for Checacin1. Whereas Checacin $1^{1-11}$ and Checacin $1^{12-25}$ caused no visible effects to the cell culture (Figure $4 a, b)$ at the highest applied concentration $(100 \mu \mathrm{M})$, Checacin1 and C-terminally truncated Checacin $1^{1-21}$ caused a nearly complete disintegration of the cell layer (Figure $4 \mathrm{c}, \mathrm{d}$ ). This was confirmed for both peptides by the significantly lower luminescence compared to the negative control. This is indicative of a strong decline of the cell's ATP content (Figure 3). For Checacin1, significant cytotoxic effects could also be demonstrated at the lower concentrations $50 \mu \mathrm{M}$ and $25 \mu \mathrm{M}$, however with a relatively high standard deviation in case of the measured luminescence for the $25 \mu \mathrm{M}$ concentration. For C-terminally truncated Checacin $1^{1-21}$, a concentration of $50 \mu \mathrm{M}$ does not cause significant cytotoxic effects anymore.

Table 1. Minimum inhibitory concentrations (MIC) of Checacin1 and Checacin1 fragments determined for different microbes (Ec: Escherichia coli, Pa: Pseudomonas aeruginosa, Ms: Mycobacterium smegmatis, Sa: Staphylococcus aureus, Af: Aspergillus flavus, Ca: Candida albicans). CAMH-II: cationadjusted Mueller Hinton II medium; CAMH-C: CAMH-II with $44 \mathrm{mM}$ sodium bicarbonate; TEM-1: TEM-1 beta-lactamase expressing strain; MRSA: methicillin-resistant Staphylococcus aureus; BTG: BacTiter-Glo ${ }^{\mathrm{TM}}$-assay; MTT: microtiter turbidity assay.

\begin{tabular}{|c|c|c|c|c|c|c|c|}
\hline \multirow[t]{4}{*}{ Compounds } & \multicolumn{7}{|c|}{ MIC $(\mu \mathrm{M})$} \\
\hline & \multicolumn{2}{|c|}{$E c$} & $P a$ & Ms & $S a$ & Af & $C a$ \\
\hline & \multicolumn{2}{|c|}{ ATCC 35218} & ATCC27853 & ATCC607 & ATCC33592 & ATCC9170 & FH2173 \\
\hline & TEM-1 & TEM-1 & & & MRSA & & \\
\hline & CAMHII & CAMH-C & CAMHII & CAMHII & CAMHII & CAMHII & CAMHII \\
\hline Checacin1 & $1.6-0.8$ & 1.6 & 12.5 & 25 & 1.6 & 50 & 6.25 \\
\hline Checacin $1^{1-11}$ & $>50$ & $>50$ & $>50$ & $>50$ & $>50$ & $>50$ & $>50$ \\
\hline Checacin $1^{12-25}$ & $>50$ & $>50$ & $>50$ & $>50$ & $>50$ & $>50$ & $>50$ \\
\hline Checacin $1^{1-21}$ & $>50$ & $>50$ & $>50$ & $>50$ & 12.5 & $>50$ & $>50$ \\
\hline Rifampicin & 4.9 & 19.4 & 38.9 & 38.9-19.4 & $>77.8$ & NA & NA \\
\hline Tetracycline & 4.5 & $36-18$ & $>144.1$ & 0.14 & $>72$ & NA & NA \\
\hline Gentamycin */Isoniazid " & $2.1-1$ & $1-0.5$ & 1 & $29.2-14.6^{\prime \prime}$ & $0.5-0.26$ & NA & NA \\
\hline Tebuconazole & NA & NA & NA & NA & NA & 0.19 & $0.19-0.09$ \\
\hline Amphotericin B & NA & NA & NA & NA & NA & 1.1 & $8.6-4.3$ \\
\hline Nystatin & NA & NA & NA & NA & NA & 1.1 & 8.6 \\
\hline readout & MTT & MTT & MTT & BTG & MTT & BTG & BTG \\
\hline
\end{tabular}

${ }^{*}$ Calculated for gentamycin C1 (25876-10-2) as gentamycin (1405-41-0) is a substance mixture. " Mycobacterium smegmatis was tested against isoniazid instead of gentamycin. 

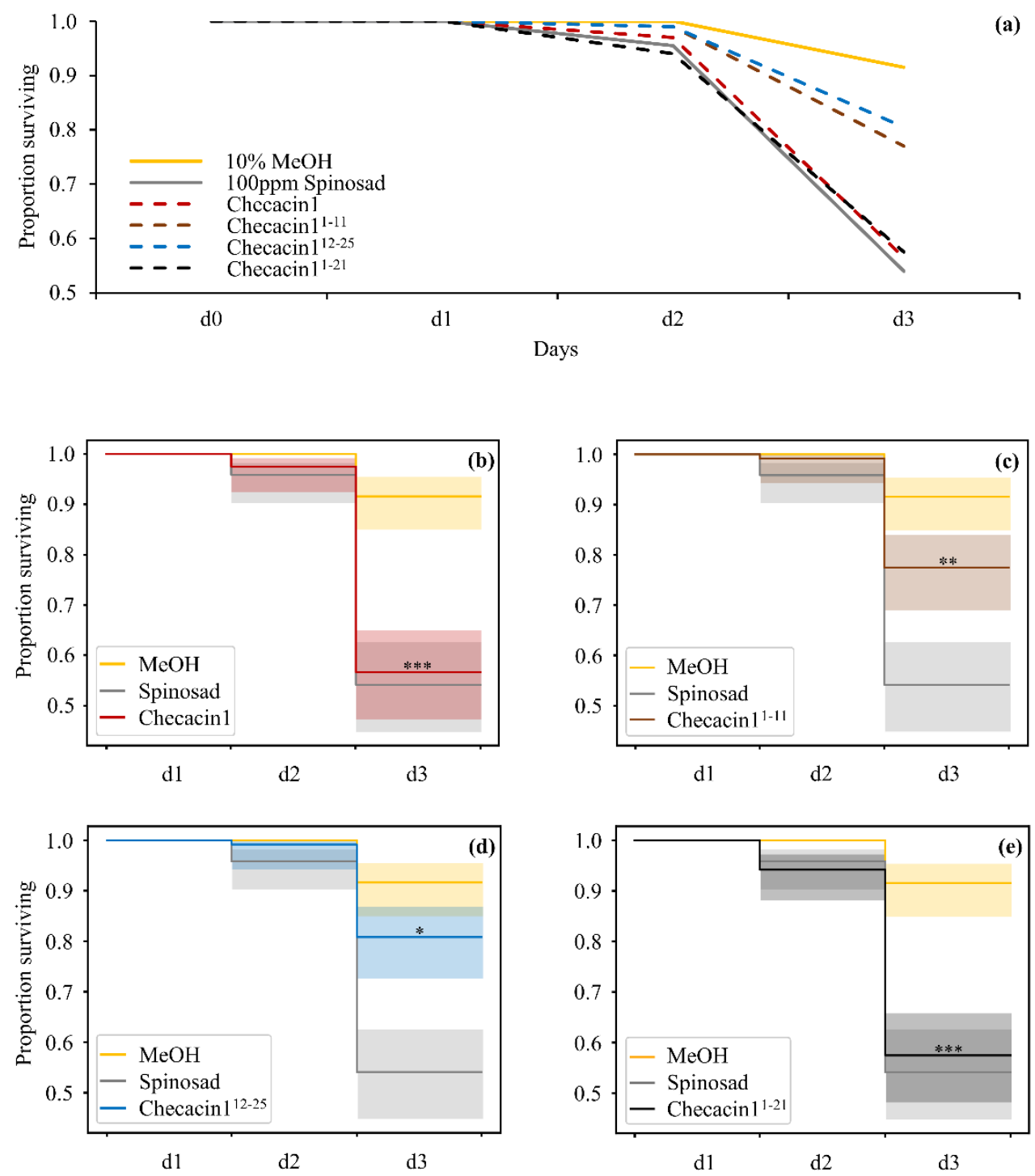

Figure 2. Survival curves of pea aphids (A. pisum) after oral administration of Checacin1 and its fragments. Aphids were monitored for three days. As negative control, aphids were fed with $10 \%$ methanol $(\mathrm{MeOH})$ and a commercial pesticide was used as positive control (Spinosad). (a) Line chart comparing mean survival rates of all tested components with negative and positive control. Checacin 1 and Checacin $1^{1-21}$, but not the shorter Checacin 1 fragments, were recovered as insecticidal (b-e) Survival rates of individual components with included $95 \%$ confidence interval. Significant differences to the negative controls were assessed by a log-rank test and are indicated by ${ }^{\text {‘* }}$ for $p<0.1$, ‘**' for $p<0.05$ and '***' for $p<0.01$ (Table S1). 


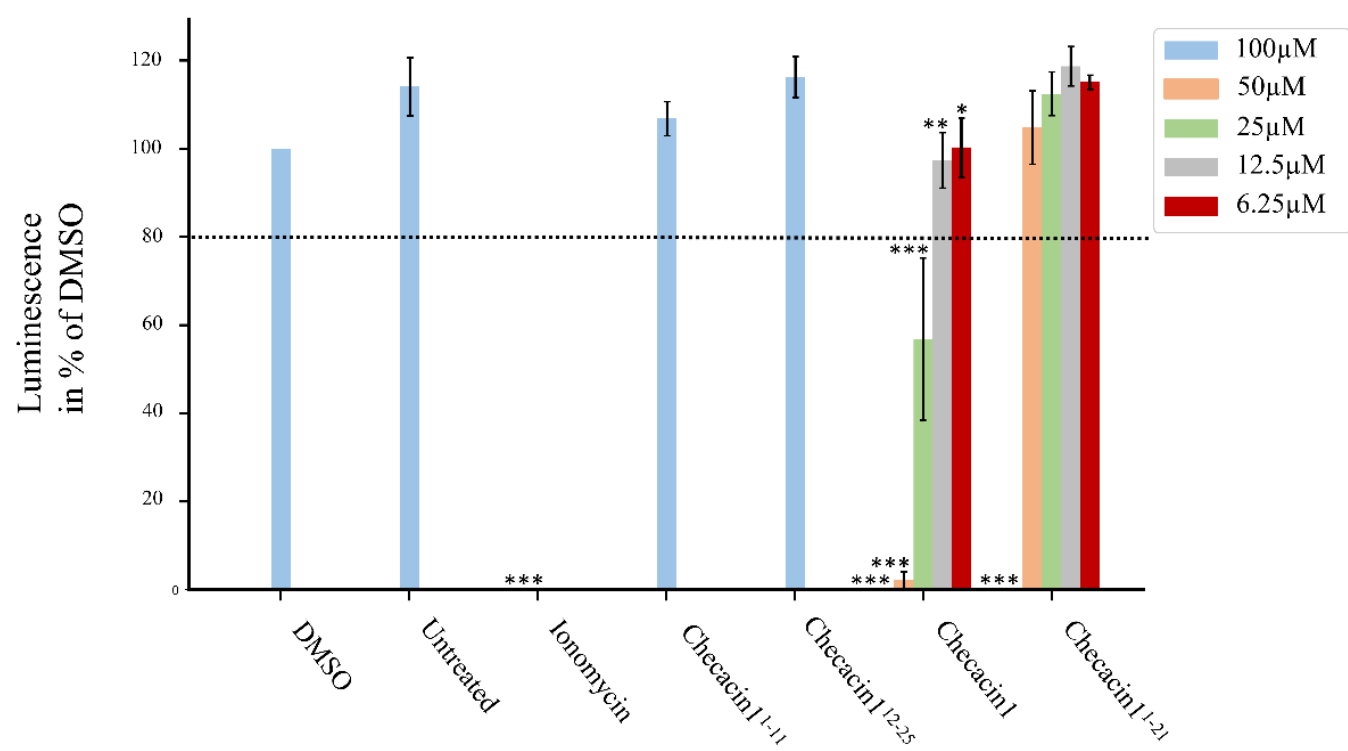

Figure 3. Cell viability assay of MDCK II cells treated with varying concentrations of Checacin1 and Checacin1 fragments. Cell viability was assessed based on CellTiter-Glo ${ }^{\circledR}$ (Promega GmbH, Walldorf, Germany) which measures luminescence as an indicator for ATP amount. The luminescence signal of the $100 \mu \mathrm{M}$ treatment of Checacine 1 and Checacin $1^{1-21}$ was at $0 \%$ and therefore not detectable. Luminescence was normalized to the DMSO control; data are presented as mean \pm SD ( $n=4-6)$. DMSO: dimethyl sulfoxide. Significant differences to the negative control (Untreated) were assessed by t-statistics and are indicated by ${ }^{\prime * \prime}$ for $p<0.1,^{\text {'**' }}$ for $p<0.05$ and ${ }^{\text {***' }}$ for $p<0.01$.
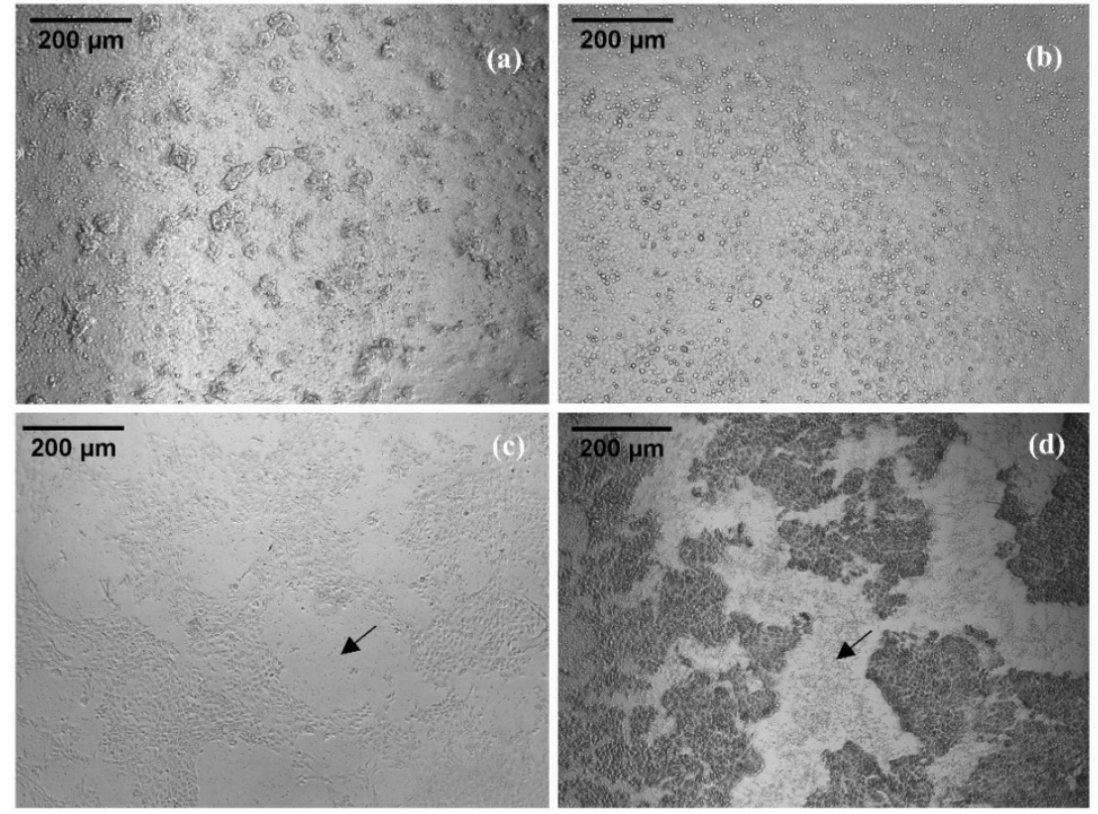

Figure 4. Madin-Darby canine kidney II (MDCK II) cell culture after application of $100 \mu \mathrm{M}$ Checacin1 and its truncated forms. $(\mathbf{a}, \mathbf{b})$ : intact cell layer after application of Checacin $1^{1-11}$ and Checacin $1^{12-25}$ $(\mathbf{c}, \mathbf{d})$ : disintegrated cell layer after application of Checacin $1^{1-21}$ and Checacin1. Arrows indicate areas of disintegrated cell layers.

\section{Discussion}

This study provides first insights into the bioactivity of checacins, AMPs identified in the venom of the pseudoscorpion C. cancroides. By now, precursors of seven checacin genes were identified from this species $[22,23]$. These checacin genes show highly different expression levels which is also reflected by the relative intensities of the ion signals of 
the mature peptides in MALDI-TOF mass fingerprints. For our activity tests, we selected Checacin1, which is the most prominent checacin in terms of expression level as well as signal intensity in MALDI-TOF mass spectra of venom samples [22]. Additional peptides used in this study are truncated forms of Checacin1. Two of these peptides represent naturally occurring fragments of Checacin 1 , whereas synthetic Checacin $1^{1-21}$ is a peptide that was not yet found in the venom of $C$. cancroides. This peptide was tested because AMPs from orthologous scorpion genes (megicin, marcin etc.) were described without the existing basic C-terminus [20]. These peptides have already been synthesized and activity tests resulted in promising antimicrobial activities, including a successful therapy of mice infected with multi-drug-resistant Gram-positive bacteria [13]. Figure 5 shows an alignment of partial checacin precursors from $C$. cancroides with those of partial precursors of the scorpion AMPs megicin and marcin.

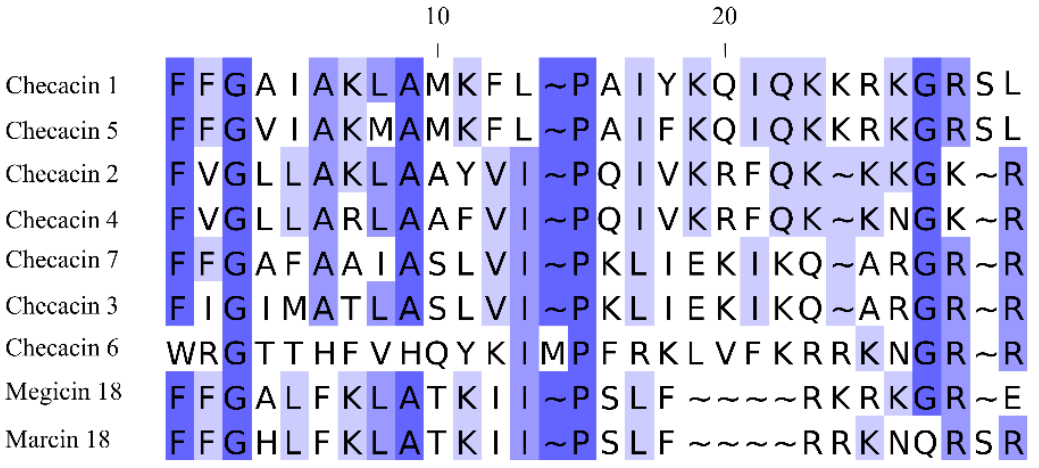

Figure 5. Alignment of the checacin motif, identified in pseudoscorpion venom with orthologs discovered in scorpion venom. Sequences include glycin as amidation signal (if present) and the C-terminal cleavage site. The coloration indicates percentage of identity.

As many AMPs found in arachnid venoms, checacins are linear cationic peptides. Such peptides mostly exert their toxic effects by binding to cell membranes and causing the formation of pores, leading to cell death [25]. A crucial factor for the pore forming ability is the hydrophobic N-terminus, whereas the specificity for different membranes is mainly determined by the net charge of the peptide [25]. As bacterial cell membranes exhibit a more negative net charge than, e.g., animal cell membranes, cationic peptides bind to these with higher affinity [26]. In the venom, such peptides were first believed to function solely as conserving agents which protect the venom peptides against a wide range of microorganisms [27]. As linear cationic peptides often also exhibit cytotoxic activities on the potential prey, an active participation as, e.g., spreading factors [28] in envenomation cannot be excluded and the already postulated 'dual-use'-concept [29] might be the best approximation to explain the mode of action of the majority of these peptides.

In our tests, antimicrobial activities were only observed for full length Checacin1 and in part for Checacin $1^{1-21}$. The highest applied concentrations of the shorter checacin fragments did not cause any antimicrobial effects on the tested strains. This can be explained by the following assumptions: in case of Checacin ${ }^{1-11}$, the lower net charge reduces antimicrobial activity, whereas Checacin $1^{12-25}$ is lacking the hydrophobic N-terminus. Checacin $1^{1-21}$ is also much less active against the tested strains and only efficient on S. aureus. As this peptide lacks the C-terminus, the reduced antimicrobial activity might also be explained by the reduced positive net charge. The C-terminal amidation improves peptide stability by protecting the peptide from proteolytic cleavage. In the case of the checacin precursors, the use of the monobasic Arg cleavage signal following Gly may have been subject to positive selection during the evolution of the checacins. It was shown in a previous study, that synthetic scorpion AMPs are effective against aphids by acting on their symbiotic bacteria [14]. Interestingly, both Checacin1 and Checacin $1^{1-21}$ killed aphids with similar efficiency, though the antimicrobial efficacy of Checacin $1^{1-21}$ is much weaker. The N- and C-terminal fragments of Checacin1 also had a weak but significant effect on 
aphid survival without noticeably affecting any of the microbes tested. This indicates that at least some of the tested Checacin 1 fragments exert their insecticidal activity on aphids by directly affecting the aphid cells and not the symbiotic bacteria. Nevertheless, the aphid's symbionts were not yet among the tested strains, and the peptide concentrations used in the aphid assay were mostly higher than the concentrations applied in the antimicrobial tests. Regarding the cytotoxicity for mammalian cells, mainly Checacin1 showed cytotoxic effects in the tested concentration range. Cytotoxic effects caused by AMPs were observed frequently in the past, e.g., [21]. Interestingly, the mechanism by which AMPs act on most mammalian cells is usually apoptosis and not cell lysis as observed for bacterial cells and erythrocytes [30]. A requirement for pharmaceutic application of AMPs is a MIC lower than the minimal concentration causing cytotoxic effects in mammals [31]. In case of Checacin1, the minimal cytotoxic concentration is between $25 \mu \mathrm{M}$ and $12.5 \mu \mathrm{M}$, which is one order of magnitude above the observed MICs of E. coli and S. aureus. Due to this minimal therapeutic window, pharmaceutical application would require further optimization. However, in the current study cytotoxicity was tested with MDCK II cells from dogs and the effect on human cells has still to be examined. Bacalum and Radu (2015) recommended to test cytotoxicity on erythrocytes and lymphocytes to consider apoptotic effects caused by AMPs [30]. A yet unresolved question regarding differential expression of the checacins is to what extent the relative abundance of the checacins correlates with specificity or efficiency toward their target cells. In this regard, three hypotheses seem plausible: (1) The highly abundant checacins are the most efficient, which would explain the higher energy investment of increased production. (2) Less abundant checacins are more efficient and due to their higher efficacy, higher concentrations are not necessary to fulfil their functions. It has been postulated previously, that venoms contain toxins with low abundance, that are equally important as the products of highly expressed venom compounds e.g., [32]. (3) The ratio of checacins in the venom might lead to an optimal efficiency. This idea might be supported by findings that demonstrated synergistic effects of venom compounds, e.g., [33].

\section{Conclusions}

The venom of neglected arthropods provides an additional source of novel AMPs, which are promising candidates for developing alternative pesticides or antibiotics. For full-length Checacin1, the most prominent AMP present in the venom of the pseudoscorpion C. cancroides, we observed promising antimicrobial activities against several clinically relevant strains of bacteria and fungi. In feeding assays, Checacin1 and C-terminal truncated Checacin $1^{1-21}$ efficiently reduced aphid survival, suggesting that these peptides have potential as novel pesticides, although their selectivity for pest insects needs to be explored further. As known for linear cationic peptides, the cell membrane disrupting capability of Checacin1 relies on its hydrophobic N-terminus as well as on the high net charge, which is demonstrated by the much lower efficacy observed for Checacin1 fragments. So far, we have only tested the activity of one out of seven known C. cancroides checacins. As these peptides differ substantially in terms of gene expression level, it would be interesting to test, how this is correlated with the efficiency and specificity of the different checacins.

\section{Material and Methods}

\subsection{Peptide Synthesis}

Synthetic peptides were obtained from DGpeptides Co., Ltd. (Hangzhou, China). Purities and identifiers used by the company are shown in Table 2.

\subsection{Feeding Assay on Pea Aphids (A. pisum)}

Screenings for potential insecticidal activities were performed as feeding assays on age synchronized pea aphids (A. pisum, clone LL01, 5 days old) as described by Heep and colleagues $[34,35]$. Pea aphid nymphs were fed on an artificial diet [36], containing the tested checacins (100 ppm), in specialized feeding chambers [37] for three days. We used diet mixtures 
containing 10\% methanol as negative control and Spinosad (100 ppm) as positive control. Pea aphid survival was scored daily. The feeding assay was performed in three biological replicates per substance and control, each containing a total of $60 \mathrm{~A}$. pisum specimen.

Table 2. List of antimicrobial peptides synthesized based on peptides identified in the venom of the pseudoscorpion Chelifer cancroides.

\begin{tabular}{|c|c|c|}
\hline Component/Company ID & Sequence & Purity \\
\hline Checacin1/D-4040 & FFGAIAKLAMKFLPAIYKQIQKKRK * & $96.75 \%$ \\
\hline Checacin $1^{1-11} / \mathrm{D}-4041$ & FFGAIAKLAMK & $97.84 \%$ \\
\hline Checacin $1^{12-25} / \mathrm{D}-4042$ & FLPAIYKQIQKKRK * & $98.07 \%$ \\
\hline Checacin $1^{1-21} / \mathrm{D}-4043$ & FFGAIAKLAMKFLPAIYKQIQ & $96.87 \%$ \\
\hline
\end{tabular}

* Sequence with C-terminal amidation.

\subsection{Antimicrobial Activity Assays}

The antimicrobial properties of the synthesized checacins were evaluated against a diverse set of indicator strains. The used method for minimum inhibitory concentrations (MIC) determination is derived from the methodology proposed by the EUCAST committee. The antibacterial/antifungal MIC value is defined as the lowest concentration of an agent that inhibits the growth of a microorganism by $85 \%$ relative to the growth controls (High value). The medium background (low value) is subtracted from all measurements ( $A U=$ absorption units; luminescence for cell viability assays). Relative growth inhibition is calculated according to:

$$
\text { rel.growth inhibtion }[\%]=100 \times\left(1-\frac{A U_{\text {sample }}-A U_{\text {Low }}}{A U_{\text {High }}-A U_{\text {Low }}}\right)
$$

$A U=$ absorption units, low = medium blank, high = growth control .

The peptides were dissolved in sterile ultra-pure water $(0.055 \mu \mathrm{S} / \mathrm{cm})$ and tested in a 12 step dilution series ranging from 50 to $0.02 \mu \mathrm{M}$. All concentrations were tested in triplicate.

Escherichia coli ATCC35218, Staphylococcus aureus ATCC33592 MRSA and Pseudomonas aeruginosa ATCC27853 were incubated overnight $\left(37^{\circ} \mathrm{C}, 180\right.$ rotations per minute (rpm) and subsequently diluted to $5 \times 10^{5}$ cells $/ \mathrm{mL}$ in cation adjusted Mueller Hinton II medium (Becton Dickinson, Sparks, NV, USA). For E. coli ATCC35218 an additional cell suspension was prepared in cation adjusted Mueller Hinton II medium supplemented with $44 \mathrm{mM}$ sodium bicarbonate. As positive controls dilution series of rifampicin, tetracycline and gentamycin (all Sigma Aldrich, St. Louis, MS, USA), ranging from 64-0.03 $\mu \mathrm{g} / \mathrm{mL}$, were used. Bacterial suspensions without peptide or antibiotic control were used as negative controls. After assay incubation $\left(37^{\circ} \mathrm{C}, 180 \mathrm{rpm}, 85 \%\right.$ relative humidity (r.H.)), cell growth was assessed by measuring the turbidity with a microplate spectrophotometer at $600 \mathrm{~nm}$ (LUMIstar ${ }^{\circledR}$ Omega BMG Labtech, Ortenberg, Germany). Growth inhibition was calculated relative to the absorption of the controls. The pre culture of Mycobacterium smegmatis ATCC607 was incubated in brain-heart infusion broth (Becton Dickinson, Sparks, NV, USA) for $48 \mathrm{~h}$, at $37^{\circ} \mathrm{C}$ and $180 \mathrm{rpm}$ before the cell concentration was adjusted in Mueller Hinton II medium. Isoniazid (Sigma Aldrich, St. Louis, MS, USA) was used instead of gentamycin as third positive control. Cell viability was evaluated after $48 \mathrm{~h}\left(37^{\circ} \mathrm{C}, 180 \mathrm{rpm}\right.$, $85 \%$ r.H.) via ATP quantification (BacTiter-Glo ${ }^{\mathrm{TM}}$, Promega, Madison, WI, USA) according to the manufacturer's instructions. Candida albicans FH2173 was incubated for $48 \mathrm{~h}$ at $28{ }^{\circ} \mathrm{C}$ and $180 \mathrm{rpm}$ before the pre culture was diluted to $1 \times 10^{6}$ cells $/ \mathrm{mL}$ in Mueller Hinton II medium. For Aspergillus flavus ATCC9170, a previously prepared spore solution was used to adjust the assay inoculum to $1 \times 10^{5}$ spores $/ \mathrm{mL}$. Assays were incubated for $48 \mathrm{~h}$ at $37^{\circ} \mathrm{C}$ and $180 \mathrm{rpm}$. For both, tebuconazole (Cayman Chemical Company, Ann Arbor, MI, USA), amphotericin B and nystatin (both Sigma Aldrich, St. Louis, MS, USA) were used as a positive control $(64-0.03 \mu \mathrm{g} / \mathrm{mL})$. Readout was performed by way of ATP quantification. 


\subsection{Cytotoxicity Assays}

\subsubsection{Cell Culture}

Madin-Darby canine kidney II (MDCK II) cells [38] were maintained in Dulbecco's modified Eagle's medium (DMEM GlutaMAX, ThermoFisher, Waltham, MA, USA) supplemented with $1 \%$ penicillin/streptomycin (ThermoFisher) and $10 \%$ fetal calf serum (ThermoFisher) and grown in an incubator at $37^{\circ} \mathrm{C}$ with $5 \% \mathrm{CO}_{2}$. The MDCK II cell line was kindly provided by Prof. Dr. Friebertshäuser (Philipps University Marburg, Institute of Viorology, Marburg, Germany).

\subsubsection{Cell Viability Assays}

Checacins and Ionomycin (Cayman Chemicals, Ann Arbor, MI, USA) were dissolved in DMSO and Aprotinin (Carl Roth, GmbH \& co KG, Karlsruhe, Germany) was dissolved in water (stock solutions: $10 \mathrm{mM}$ ).

For the cell viability assay MDCK II cells were seeded in a 96-well plate and treated at a confluence of $90 \%$ with the indicated inhibitors $(100 \mu \mathrm{M}$ per well) or DMSO control. The plate was incubated at $37{ }^{\circ} \mathrm{C}$ and $5 \% \mathrm{CO}_{2}$. The cell viability was assessed by measuring the ATP content using the CellTiter-Glo Luminescent Cell Viability assay (Promega GmbH, Walldorf, Germany) according to the manufacturer's instructions. Luminescence was measured using a black 96-well plate in a Synergy H4 microplate reader (Biotek, Waldbronn, Germany, now part of Agilent Technologies). Relative light units (RLU) were normalized to DMSO control set to $100 \%$. Measurements were conducted with four to six replicates and standard deviations were calculated.

Supplementary Materials: The following supporting information can be downloaded at: https:/ / www.mdpi.com/article/10.3390/toxins14010058/s1, Table S1: 'Aphid Raw Data', Table S2: 'Cytotox Raw Data'.

Author Contributions: Conceptualization, J.K., A.V., T.L. and R.P.; methodology, T.L., M.M.; formal analysis, J.K., M.M., K.H., E.M., J.E.; investigation, K.H., E.M., J.E.; resources, K.H., T.F.S., A.V.; writing—original draft preparation, J.K. and R.P.; writing—review and editing, T.L., A.V., K.H., M.M., T.F.S.; visualization, J.K.; supervision, R.P.; project administration, T.L.; funding acquisition, A.V. All authors have read and agreed to the published version of the manuscript.

Funding: J.K. received funding from the Studienstiftung des deutschen Volkes. The present work is a result of the Centre for Translational Biodiversity Genomics (LOEWE-TBG) and was granted to A.V. through the programme "LOEWE-Landes-Offensive zur Entwicklung WissenschaftlichÖkonomischer Exzellenz" of Hesse's Ministry of Higher Education, Research, and the Arts. K.H., E.M. and J.E. were supported by the BMBF project "ASCRIBE".

Institutional Review Board Statement: Not applicable.

Data Availability Statement: Data is contained within the article and the Supplementary Materials.

Acknowledgments: We thank Tobias Kessel for his support in the aphid feeding experiments.

Conflicts of Interest: The authors declare no conflict of interest.

\section{References}

1. Cassini, A.; Högberg, L.D.; Plachouras, D.; Quattrocchi, A.; Hoxha, A.; Simonsen, G.S.; Colomb-Cotinat, M.; Kretzschmar, M.E.; Devleesschauwer, B.; Cecchini, M.; et al. Attributable Deaths and Disability-Adjusted Life-Years Caused by Infections with Antibiotic-Resistant Bacteria in the EU and the European Economic Area in 2015: A Population-Level Modelling Analysis. Lancet Infect. Dis. 2019, 19, 56-66. [CrossRef]

2. Bahar, A.; Ren, D. Antimicrobial Peptides. Pharmaceuticals 2013, 6, 1543-1575. [CrossRef]

3. Ortiz, E.; Gurrola, G.B.; Schwartz, E.F.; Possani, L.D. Scorpion Venom Components as Potential Candidates for Drug Development. Toxicon 2015, 93, 125-135. [CrossRef]

4. de Barros, E.; Gonçalves, R.M.; Cardoso, M.H.; Santos, N.C.; Franco, O.L.; Cândido, E.S. Snake Venom Cathelicidins as Natural Antimicrobial Peptides. Front. Pharmacol. 2019, 10, 1415. [CrossRef] [PubMed]

5. Ebou, A.; Koua, D.; Addablah, A.; Kakou-Ngazoa, S.; Dutertre, S. Combined Proteotranscriptomic-Based Strategy to Discover Novel Antimicrobial Peptides from Cone Snails. Biomedicines 2021, 9, 344. [CrossRef] [PubMed] 
6. Wu, Q.; Patočka, J.; Kuča, K. Insect Antimicrobial Peptides, a Mini Review. Toxins 2018, 10, 461. [CrossRef]

7. Harrison, P.L.; Abdel-Rahman, M.A.; Miller, K.; Strong, P.N. Antimicrobial Peptides from Scorpion Venoms. Toxicon 2014, 88, 115-137. [CrossRef] [PubMed]

8. Santos, D.M.; Reis, P.V.; Pimenta, A.M.C. Antimicrobial Peptides in Spider Venoms. In Spider Venoms; Gopalakrishnakone, P., Corzo, G.A., de Lima, M.E., Diego-García, E., Eds.; Springer: Dordrecht, The Netherlands, 2016; pp. 361-377. ISBN 978-94-007-6388-3.

9. Lüddecke, T.; Herzig, V.; Reumont, B.M.; Vilcinskas, A. The Biology and Evolution of Spider Venoms. Biol. Rev. 2021, 163-178. [CrossRef] [PubMed]

10. Abd El-Wahed, A.; Yosri, N.; Sakr, H.H.; Du, M.; Algethami, A.F.M.; Zhao, C.; Abdelazeem, A.H.; Tahir, H.E.; Masry, S.H.D.; AbdelDaim, M.M.; et al. Wasp Venom Biochemical Components and Their Potential in Biological Applications and Nanotechnological Interventions. Toxins 2021, 13, 206. [CrossRef] [PubMed]

11. Zhao, Z.; Zhang, K.; Zhu, W.; Ye, X.; Ding, L.; Jiang, H.; Li, F.; Chen, Z.; Luo, X. Two New Cationic $\alpha$-Helical Peptides Identified from the Venom Gland of Liocheles australasiae Possess Antimicrobial Activity against Methicillin-Resistant Staphylococci. Toxicon 2021, 196, 63-73. [CrossRef] [PubMed]

12. Luna-Ramírez, K.; Sani, M.-A.; Silva-Sanchez, J.; Jiménez-Vargas, J.M.; Reyna-Flores, F.; Winkel, K.D.; Wright, C.E.; Possani, L.D.; Separovic, F. Membrane Interactions and Biological Activity of Antimicrobial Peptides from Australian Scorpion. Biochim. Biophys. Acta BBA Biomembr. 2014, 1838, 2140-2148. [CrossRef]

13. Liu, G.; Yang, F.; Li, F.; Li, Z.; Lang, Y.; Shen, B.; Wu, Y.; Li, W.; Harrison, P.L.; Strong, P.N.; et al. Therapeutic Potential of a Scorpion Venom-Derived Antimicrobial Peptide and Its Homologs Against Antibiotic-Resistant Gram-Positive Bacteria. Front. Microbiol. 2018, 9, 1159. [CrossRef] [PubMed]

14. Luna-Ramirez, K.; Skaljac, M.; Grotmann, J.; Kirfel, P.; Vilcinskas, A. Orally Delivered Scorpion Antimicrobial Peptides Exhibit Activity against Pea Aphid (Acyrthosiphon pisum) and Its Bacterial Symbionts. Toxins 2017, 9, 261. [CrossRef]

15. Van Emden, H.F.; Harrington, R. (Eds.) Aphids as Crop Pests, 2nd ed.; CABI: Wallingford/Oxfordshire, UK; Boston, MA, USA, 2017; ISBN 978-1-78064-709-8.

16. Harvey, M.S. Pseudoscorpions of the World, Version 3.0. Available online: http://www.museum.wa.gov.au/catalogues/ pseudoscorpions (accessed on 29 November 2021).

17. Ontano, A.Z.; Gainett, G.; Aharon, S.; Ballesteros, J.A.; Benavides, L.R.; Corbett, K.F.; Gavish-Regev, E.; Harvey, M.S.; Monsma, S.; Santibáñez-López, C.E.; et al. Taxonomic Sampling and Rare Genomic Changes Overcome Long-Branch Attraction in the Phylogenetic Placement of Pseudoscorpions. Mol. Biol. Evol. 2021, 38, 2446-2467. [CrossRef] [PubMed]

18. Lüddecke, T.; Vilcinskas, A.; Lemke, S. Phylogeny-Guided Selection of Priority Groups for Venom Bioprospecting: Harvesting Toxin Sequences in Tarantulas as a Case Study. Toxins 2019, 11, 488. [CrossRef] [PubMed]

19. Santibáñez-López, C.; Ontano, A.; Harvey, M.; Sharma, P. Transcriptomic Analysis of Pseudoscorpion Venom Reveals a Unique Cocktail Dominated by Enzymes and Protease Inhibitors. Toxins 2018, 10, 207. [CrossRef]

20. Lebenzon, J.E.; Toxopeus, J.; Anthony, S.E.; Sinclair, B.J. De Novo Assembly and Characterisation of the Transcriptome of the Beringian Pseudoscorpion. Can. Entomol. 2021, 153, 301-313. [CrossRef]

21. Smith, J.; Undheim, E. True Lies: Using Proteomics to Assess the Accuracy of Transcriptome-Based Venomics in Centipedes Uncovers False Positives and Reveals Startling Intraspecific Variation in Scolopendra subspinipes. Toxins 2018, 10, 96. [CrossRef]

22. Krämer, J.; Pohl, H.; Predel, R. Venom Collection and Analysis in the Pseudoscorpion Chelifer cancroides (Pseudoscorpiones: Cheliferidae). Toxicon 2019, 162, 15-23. [CrossRef]

23. Krämer, J.; Peigneur, S.; Tytgat, J.; Jenner, R.A.; van Toor, R.; Predel, R. A Pseudoscorpion's Promising Pinch: The Venom of Chelifer cancroides Contains a Rich Source of Novel Compounds. Toxicon 2021, S0041010121002233. [CrossRef] [PubMed]

24. Diego-García, E.; Caliskan, F.; Tytgat, J. The Mediterranean Scorpion Mesobuthus gibbosus (Scorpiones, Buthidae): Transcriptome Analysis and Organization of the Genome Encoding Chlorotoxin-like Peptides. BMC Genom. 2014, 15, 295. [CrossRef]

25. Hancock, R.E.W.; Falla, T.; Brown, M. Cationic Bactericidal Peptides. In Advances in Microbial Physiology; Elsevier: Amsterdam, The Netherlands, 1995; Volume 37, pp. 135-175. ISBN 978-0-12-027737-7.

26. Yeaman, M.R.; Yount, N.Y. Mechanisms of Antimicrobial Peptide Action and Resistance. Pharmacol. Rev. 2003, 55, 27-55. [CrossRef]

27. Shafee, T.M.A.; Lay, F.T.; Phan, T.K.; Anderson, M.A.; Hulett, M.D. Convergent Evolution of Defensin Sequence, Structure and Function. Cell. Mol. Life Sci. 2017, 74, 663-682. [CrossRef]

28. Kuhn-Nentwig, L.; Langenegger, N.; Heller, M.; Koua, D.; Nentwig, W. The Dual Prey-Inactivation Strategy of Spiders-In-Depth Venomic Analysis of Cupiennius salei. Toxins 2019, 11, 167. [CrossRef]

29. Lüddecke, T.; Schulz, S.; Steinfartz, S.; Vences, M. A Salamander's Toxic Arsenal: Review of Skin Poison Diversity and Function in True Salamanders, Genus Salamandra. Sci. Nat. 2018, 105, 56. [CrossRef] [PubMed]

30. Bacalum, M.; Radu, M. Cationic Antimicrobial Peptides Cytotoxicity on Mammalian Cells: An Analysis Using Therapeutic Index Integrative Concept. Int. J. Pept. Res. Ther. 2015, 21, 47-55. [CrossRef]

31. Chen, Y.; Mant, C.T.; Farmer, S.W.; Hancock, R.E.W.; Vasil, M.L.; Hodges, R.S. Rational Design of $\alpha$-Helical Antimicrobial Peptides with Enhanced Activities and Specificity/Therapeutic Index. J. Biol. Chem. 2005, 280, 12316-12329. [CrossRef]

32. Gremski, L.H.; da Silveira, R.B.; Chaim, O.M.; Probst, C.M.; Ferrer, V.P.; Nowatzki, J.; Weinschutz, H.C.; Madeira, H.M.; Gremski, W.; Nader, H.B.; et al. A Novel Expression Profile of the Loxosceles intermedia Spider Venomous Gland Revealed by Transcriptome Analysis. Mol. Biosyst. 2010, 6, 2403. [CrossRef] [PubMed] 
33. Wullschleger, B.; Kuhn-Nentwig, L.; Tromp, J.; Kampfer, U.; Schaller, J.; Schurch, S.; Nentwig, W. CSTX-13, a Highly Synergistically Acting Two-Chain Neurotoxic Enhancer in the Venom of the Spider Cupiennius salei (Ctenidae). Proc. Natl. Acad. Sci. USA 2004, 101, 11251-11256. [CrossRef] [PubMed]

34. Heep, J.; Skaljac, M.; Grotmann, J.; Kessel, T.; Seip, M.; Schmidtberg, H.; Vilcinskas, A. Identification and Functional Characterization of a Novel Insecticidal Decapeptide from the Myrmicine Ant Manica rubida. Toxins 2019, 11, 562. [CrossRef]

35. Heep, J.; Klaus, A.; Kessel, T.; Seip, M.; Vilcinskas, A.; Skaljac, M. Proteomic Analysis of the Venom from the Ruby Ant Myrmica rubra and the Isolation of a Novel Insecticidal Decapeptide. Insects 2019, 10, 42. [CrossRef] [PubMed]

36. Akey, D.H.; Beck, S.D. Continuous Rearing of the Pea Aphid, Acyrthosiphon pisum,1 on a Holidic Diet2. Ann. Entomol. Soc. Am. 1971, 64, 353-356. [CrossRef]

37. Sadeghi, A.; Van Damme, E.J.M.; Smagghe, G. Evaluation of the Susceptibility of the Pea Aphid, Acyrthosiphon pisum, to a Selection of Novel Biorational Insecticides Using an Artificial Diet. J. Insect Sci. 2009, 9, 1-8. [CrossRef] [PubMed]

38. Barker, G.; Simmons, N.L. Identification of two Strains of Cultured Canine Renal Epithelial Cells (MDCK Cells) which Display Entirely Different Physiological Properties. Q. J. Exp. Physiol. 1981, 66, 61-72. [CrossRef] [PubMed] 